\title{
Inequalities in oral health and oral health promotion*
}

\section{Samuel Jorge Moysés}

School of Health and Biosciences, Pontifical Catholic University of Paraná, Curitiba, PR, Brazil.

\footnotetext{
* Paper presented at the "Oral Health Under an Integrality Perspective" International Symposium, held at the $17^{\text {th }}$ Congress of the Brazilian Association for Oral Health Promotion (ABOPREV), May 31 to June 2, 2012, Salvador, BA, Brazil.
}

Declaration of Interests: The author certifies that he has no commercial or associative interest that represents a conflict of interest in connection with the manuscript.

\section{Corresponding Author:}

Samuel Jorge Moysés

E-mails.moyses@pucpr.br

Submitted: Aug 19, 2012

Accepted for publication: Sep 03, 2012

Last revision: Sep 20, 2012

\begin{abstract}
This article offers a critical review of the problem of inequalities in oral health and discusses strategies for disease prevention and oral health promotion. It shows that oral health is not merely a result of individual biological, psychological, and behavioral factors; rather, it is the sum of collective social conditions created when people interact with the social environment. Oral health status is directly related to socioeconomic position across the socioeconomic gradient in almost all populations. The main priority for dental interventions is that they be integrated collaboratively and enable research and policies that address the main proximal determinants of oral diseases, i.e., sugars, smoking, hygiene, and risk behaviors. Adopting a mixed approach, these interventions should also reduce inequality, focusing on the socioeconomic determinants, to change the slope of the social gradient. The cornerstone of this approach is the Integrated Common Risk Factor Approach (CRFA).
\end{abstract}

Descriptors: Oral Health; Health Promotion; Epidemiologic Factors; Health Status Disparities; Socioeconomic Factors.

\section{Introduction}

This paper aims at presenting a revised theoretical framework for understanding oral health gradients and inequalities in society, and to critically review the traditional oral health approaches, supporting oral health promotion policies and practices.

The first question that should be addressed is why so little evidence is available on implementing strategies to reduce global inequalities in oral health, ${ }^{1,2}$ considering the body of available knowledge and technologies to promote health and prevent a large number of oral diseases.

A key policy rationale for reducing social inequalities is the universal finding that health indicators are better in more equal societies. It is a well-known fact that oral diseases are more common in less equal societies and among socially disadvantaged groups. ${ }^{3-5}$

In recent years, new insights have been gained into the contemporary patterns of oral health inequalities in high- and middle-income countries. Oral diseases, as is the case with other health outcomes, are socially patterned across the entire social hierarchy, a relationship known as the social gradient. ${ }^{6}$ Even in high-income countries where absolute poverty is very rare, there is a fine and graduated pattern of inequality in health across the full socioeconomic spectrum. ${ }^{7,8}$ The universal and relative stability of the social gradient therefore suggests that there is a greater gen- 
eralized susceptibility to a whole range of diseases as one descends down the social gradient. ${ }^{9}$

A social gradient in oral health has also been evidenced in a great variety of populations in several different countries, for different outcomes and at different points in the course of life of different members of society. ${ }^{6,10,11}$ The enduring nature and universality of the social gradient in health and oral health status indicates the influence of broad underlying factors rather than specific disease risks.

The reasons for the failure to put what we already know into practice effectively should head the agenda of dental organizations and government agencies. The greatest challenges in the future are to turn knowledge and experience into disease prevention and health promotion, leading to effective, scheduled action. ${ }^{12,13}$

This critical review, set down in a descriptivediscursive style, presents oral health disparities mainly determined by social factors, as evaluated by national and international literature on the subject of health inequalities. It examines the formulation of a scientific and political agenda on oral health promotion and disease prevention, with some final recommendations.

\section{Methodology}

A critical and integrative literature review was conducted from the theoretical point of view of the main social determinants of oral health and the benefits of oral health promotion. This revision was based on the criteria of quality and readability; therefore, whenever possible, we employed the RATS (Relevance, Appropriateness, Transparency and Soundness) checklist. We performed an appropriate literature search using electronic databases (PubMed/Medline and Scielo) and Boolean operators, combining the following search terms $(\mathrm{MeSH}$ and $\mathrm{DeCS})$ :

- Oral Health;

- Health Promotion;

- Epidemiologic Factors;

- Health Status Disparities;

- Socioeconomic Factors.

\section{Results and Discussion}

Most dental strategies to prevent oral diseases are directed at changing behaviors. Unsurprisingly, strategies to change behaviors have had limited positive impacts on oral health. ${ }^{14}$ Policy makers should therefore recognize that people live in behaviorshaping social, political, and economic systems and that these people should have access to the resources they need to maintain good health. ${ }^{5,15}$

It is very important to have a better understanding of the causes of people's behaviors, that is, "the causes of the causes." ${ }^{16,17}$ Why do people behave how they do?

There is interplay among intrapersonal, behavioral and environmental determinants. Behaviors are linked to the conditions in which people are born, grow, live and work, and to age. ${ }^{18}$ Although individuals make choices about how to behave, these choices are made within economic, historical, family, cultural and political contexts. Therefore, individual behaviors, commonly referred to as proximal factors, are largely influenced by social environments, and some structures make it easier to promote healthier lifestyles than others.

The shortcomings of current approaches to globally reducing inequalities and improving oral health point out the important role of social determinants, and associate these determinants to the need for research and policies in order to implement strategies to reduce oral health inequalities. Tackling inequalities in health requires strategies tailored to the determinants and needs of each group along the social gradient.

For this reason, an initiative was established in 2009 addressing the issue of social determinants and inequalities as factors influencing oral diseases, and proposing strategic interventions aimed at dealing with these problems. ${ }^{19}$ A Task Group for Implementation and Delivery of Oral Health Strategies was set up by the International Association for Dental Research (IADR) Global Oral Health Inequalities Research Agenda (GOHIRA) to identify:

a. global inequalities in oral health and disease (taking into account inequalities within as well as between countries);

b. likely reasons accounting for these oral heath in- 
equalities;

c. fundamental gaps in knowledge and understanding;

d. reasons for failure to implement at scale measures that have been shown to be effective in clinical or laboratory studies;

e. priorities for both basic and applied research;

f. a research agenda, which will lead to key improvements in global oral health, with particular reference to inequalities within and between countries.

Past strategies to tackle inequality have focused largely on either improving the health of the most deprived groups or narrowing the gap between the best- and worst-off in society. Universal strategies to address health disadvantages across the social gradient have been few. In many instances policy has focused on downstream (proximal) interventions, such as smoking cessation services or general practitioner (GP) referrals for practicing physical activities rather than tackling upstream (distal) causes such as poor living conditions and unemployment. This approach is in contrast with a wide body of epidemiological and sociological work, which suggests that health inequalities are likely to persist among socioeconomic groups even if lifestyle factors (such as smoking) are equalized.

Indeed, Phelan et al. ${ }^{20}$ suggest that the only way to achieve lasting reductions in inequality is to address society's imbalances with regard to power, income, social support and knowledge. The most effective strategy to improve health across the population, and to reduce health inequalities, is to implement upstream policy interventions that reach across sectors and create an environment (economic, social, cultural and physical) that promotes healthy living. However, these need to be supported by socially-targeted downstream interventions to mitigate any adverse distributional consequences. Some have therefore proposed a combination of both upstream and downstream solutions. ${ }^{2,21}$

Graham $^{22}$ identified a spectrum of approaches ranging from

1. remedying health disadvantages to

2. narrowing health gaps, and to
3. reducing health gradients.

The first goal commits governments to maintaining what is already a long running trend in highincome countries, namely, to securing ongoing improvement in the health of disadvantaged groups.

The second goal-to narrow health gapsis more challenging, since it requires a reversal of the trend towards widening health inequalities. To achieve this goal, the rate of a health gain among the poorest groups needs to outstrip that achieved by the comparator group (typically defined as either the most advantaged group or the population as a whole). However, while more ambitious, the goal of narrowing health gaps, like remedying health disadvantages, casts health inequalities as a condition to which only those in disadvantaged circumstances are exposed. Strategies can therefore focus solely on disadvantaged groups, seeking to improve their health in absolute terms (the more limited variant of the goal) and in relative terms.

In contrast, the goal of reducing health gradients makes it clear that health is unequally distributed, not only between the poorest groups and the better-off majority but also across all socioeconomic groups.

Concerns about determinants of health led to the setting up of the World Health Organization Commission on Social Determinants of Health - WHO/ CSDH. ${ }^{18}$ The CSDH analyzes the causes of ill health and the "causes of the causes." The CSDH provides very convincing evidence that the structural factors and conditions of daily life are the major determinants of health and inequalities in health. Health inequalities are produced/reproduced by the unjust distribution, access and effective use of income, goods and services. This directly affects the chances to enjoy life.

WHO published a global review of oral health, ${ }^{13}$ which emphasized that global problems still persist, despite great improvements in the oral health of populations in several countries. Oral diseases constitute major public health problems worldwide, and poor oral health has a profound effect on general health and quality of life. Dental caries are one of the most common chronic diseases worldwide, 
in that $90 \%$ of people have had dental problems or toothache caused by caries, and in low-to-middle income countries most caries remain untreated.

In most developing countries, the levels of dental caries were low until recent years, but prevalence rates of dental caries and dental caries experience are now tending to increase, and, among rich countries, income inequality is a stronger determinant of childhood dental caries. ${ }^{13,23-26}$ This is largely due to the increasing consumption of sugars and inadequate exposure to fluorides. In contrast, a decline in caries has been observed in most industrialized countries over the past decades. ${ }^{13}$ This pattern was the result of a number of public health measures, including effective use of fluorides, together with changing living conditions, lifestyles and improved self-care practices.

However, it must be emphasized that dental caries has not been eradicated as a children's disease, but only controlled to a certain degree. Worldwide, the prevalence of dental caries among adults is high, in that the disease affects nearly $100 \%$ of the population in the majority of countries. ${ }^{13}$ In several industrialized countries, older people have often had their teeth extracted early in life because of pain or discomfort, leading to reduced quality of life. In developing countries, oral health services are mostly offered at the regional or central hospitals of urban centers, and little, if any, importance is given to preventive or restorative dental care. Public health problems related to tooth loss and impaired oral function are therefore expected to increase in many developing countries. One worthy contemporary exception to this outlook that can be mentioned is the important investment that Brazil is making in the organization of primary care and its family health strategy, aided by oral health teams throughout the country. ${ }^{27}$

Tooth loss in adult life may also be attributable to poor periodontal health. Severe periodontitis, which may result in tooth loss, is found in $5-20 \%$ of most adult populations worldwide. Furthermore, most children and adolescents worldwide have signs of gingivitis. ${ }^{13}$ Aggressive periodontitis, which is a severe periodontal condition affecting individuals during puberty and which may lead to premature tooth loss, affects about $2 \%$ of youths.

The experience of pain, problems with eating, chewing, smiling and communication due to missing, discolored or damaged teeth has a major impact on people's daily lives and well-being. Furthermore, oral diseases restrict activities at school, at work and at home causing millions of lost school and work hours each year throughout the world.

Oral cancer is the eighth most common type of cancer worldwide, and the first most common among men in Southeast Asia. ${ }^{13}$ Furthermore, 40$50 \%$ of people who are HIV positive have oral fungal, bacterial, or viral infections. Access to oral care is a global problem, particularly in low-to-middle income countries. The workforce available to treat the most common oral health problems-dentistsare in short supply in these nations.

The diversity in oral disease patterns and development trends across countries and regions reflects distinct risk profiles and the establishment of preventive oral health care programs. The important role of sociobehavioral and environmental factors in oral health inequalities has been demonstrated in a large number of epidemiological surveys. ${ }^{13}$ In addition to poor living conditions, the major risk factors relate to unhealthy lifestyles (i.e. poor diet, nutrition and oral hygiene and use of tobacco and alcohol), and limited availability and accessibility of oral health services.

Several oral diseases are linked to noncommunicable chronic diseases, primarily because of common risk factors. ${ }^{28}$ Moreover, general diseases often have oral manifestations (e.g. diabetes or HIV/ AIDS). Worldwide strengthening of public health programs through the implementation of effective measures for the prevention of oral disease and promotion of oral health is urgently needed. The challenges of improving oral health are particularly great in developing countries. ${ }^{29}$

Traditional treatment of oral disease is extremely costly; it is the fourth most expensive disease to treat in most industrialized countries. In industrialized countries, the burden of oral disease has been tackled by establishing advanced oral health systems that primarily offer curative services to patients. Most systems are based on the demand for care, and 
oral health care is provided by private dental practitioners to patients, with or without third-party payment schemes. ${ }^{30}$

Traditional curative dental care is a significant economic burden for many industrialized countries, where $5-10 \%$ of public health expenditure relates to oral health. ${ }^{13,31,32}$ Over the past years, savings in dental expenditures have been noted in industrialized countries, which have invested in preventive oral care and where positive trends have been observed in terms of reduction in the prevalence of oral disease. In most developing countries, investment in oral health care is low. In these countries, funds are primarily allocated to emergency oral care and pain relief; if treatment were available, the costs of dental caries in children alone would exceed the total health care budget for children. ${ }^{13}$ The current global and regional patterns of oral disease largely reflect distinct risk profiles across countries, related to living conditions, lifestyles and the implementation of health promotion intersectoral actions and preventive oral health systems.

Thus, global strengthening of public health programs through the implementation of effective oral disease prevention measures and health promotion is urgently needed, and common risk factors approaches (CRFA) should be used to integrate oral health into national health programs.

The CRFA has been widely accepted and endorsed globally by dental policy makers, dental researchers and oral health promoters. ${ }^{28,30,33}$ The concept of the CRFA was originally based on health policy recommendations from the WHO in the 1980s, which encouraged an integrated approach to chronic disease prevention. In 2000, the general concept was further developed and applied to oral health with emphasis on directing action at the shared risk factors for chronic diseases, including a range of oral conditions. ${ }^{34}$ Since then, the CRFA has formed the theoretical basis for the closer integration of oral and general health strategies. Considerable progress has undoubtedly been made in combating the isolation and compartmentalization of oral health.

However, recent research and policy developments on reducing health inequalities suggest that interventions should not be limited to intermediary factors such as health behaviors, but must include policies to tackle structural determinants. ${ }^{8}$ Therefore, it is now time to critically update the CRFA in line with the social determinants agenda.

Oral health means more than just good teeth; it is integral to general health and essential for wellbeing. The strategy is that oral disease prevention and the promotion of oral health needs to be integrated with chronic disease prevention and general health promotion, insofar as the risks to health are linked..$^{14,35,36}$

Strategies to improve health have oscillated between approaches relying on narrowly defined, technology-based medical/dental high-risk approaches and public health interventions focused on tackling behavior change through health education, or on understanding health as a social phenomenon, thus requiring more complex forms of intersectoral policy action, sometimes linked to a broader social justice agenda. ${ }^{18,37-40}$

Oral health is a neglected area of global health and has traditionally ranked low on the radar of national policy makers. The reasons for this situation are complex and varied. In many countries oral health is not included in national health surveys. Moreover, if data are actually collected, they are usually isolated from the context of general health. Furthermore, in some cultures, oral health is neglected because teeth are seen as expendable. Dentists have also taken little interest in advocacy to promote good oral health, preferring to treat rather than prevent oral diseases. ${ }^{41,42}$ In addition, because poor oral health affects morbidity more than mortality, governments have viewed oral conditions as less important than other, more life-threatening diseases.

Nonetheless, globally speaking, the burden of major oral diseases and conditions is high. Dentists also cluster in cities where populations that can afford treatment usually live, leaving rural areas deprived of even the most basic emergency dental care. However, training more dentists and building dental clinics-the western curative model of care-is costly and unrealistic in most low-income and middle-income countries. Fortunately, critical changes 
begin to be observed internationally. In Brazil, some changes include dealing with the core skills of evidence-based dental practice and offering training with a more humanistic preparation in the undergraduate curriculum. ${ }^{43-45}$ Promotion of oral health and prevention of oral disease are key and largely possible, and should therefore be a routine part of the work of other health professionals.

What can be done? There are three levels of public health interventions that may be adopted to improve the health of the population: ${ }^{28,46-48}$

1. Downstream efforts comprise treatments, rehabilitation, counseling and patient education for those already experiencing some disease and disability. This is the level that, while consuming most of the available funds, encompasses a very small segment of the general population;

2. Mid-stream prevention efforts to improve a population's health should involve two main areas:

a. secondary prevention efforts that endeavor to modify the risk levels of those individuals and groups who are very likely to experience some untoward outcome;

b. primary prevention actions to encourage people not to engage in risky health-compromising behaviors that may increase their chances of experiencing a negative health event;

3. Even further upstream are healthy public policy interventions that include governmental, institutional, and organizational actions directed at entire populations requiring adequate support, by putting into place tax and fiscal structures, stipulating legal constraints and reducing barriers to personal growth, making healthy choices easier and more harmful choices more difficult, and enabling reimbursement mechanisms for those involved in health promotion and primary prevention.

The daily use of fluoride is the most cost-effective, evidence-based approach to reducing dental decay. Water or salt fluoridation is a possible population-wide approach but its implementation depends on the development and infrastructure of the country, as well as political will and community acceptance. Promoting the daily use of effective fluo- ride toothpaste is a more realistic strategy, but its costliness inhibits its widespread use in many lowincome and middle-income countries. Governments can eliminate taxes on fluoride toothpaste, which in some countries represent up to $50 \%$ of the product's price, and they can also work with manufacturers to produce lower cost toothpaste. ${ }^{49-51}$

Policies that address the risk factors for oral diseases, such as intake of sugars and tobacco use, can also be implemented, especially because these moves will help reduce chronic diseases. Oral diseases and chronic diseases, such as cardiovascular diseases, cancer, chronic respiratory diseases, and diabetes share many common risk factors. In 2007, a World Health Assembly resolution called for oral health to be integrated into chronic disease prevention programs. ${ }^{52}$

Promoting good oral health could also help countries achieve child-related development goals. Caries can negatively affect a child's ability to eat, sleep, and do school work. Preliminary studies have suggested that dental caries and related pain and sepsis might contribute to undernutrition and low weight and height in children in developing countries. In developed countries, studies show that when dental caries are treated, children start to put on weight and thrive. Oral pain is also one of the most common reasons for school absenteeism. Preventing oral disease is important and achievable. Evidence-based, simple, and cost-effective preventive approaches exist, but they need to be rigorously promoted and implemented. ${ }^{52,53}$

Professionally speaking, health workers, including physicians, nurses, pediatricians, and pharmacists can all deliver prevention messages about the use of fluoride and the risk factors for oral disease. Politically speaking, commitment is needed to integrate oral disease prevention into programs to prevent chronic diseases and into public-health systems. ${ }^{54,55}$ Good oral health should be everybody's business.

\section{Conclusions}

This paper outlined why it is essential to put the Common Risk Factor Approach (CRFA) into a broader social-determinant-related and environ- 
mental perspective, to tackle oral health inequalities. This broader perspective requires a theoretical CRFA-related expansion, insofar as there is a need to refocus health promotion approaches in order to change behaviors, by incorporating concurrent interventions at multiple levels, including individual,

\section{References}

1. Sheiham A, Alexander D, Cohen L, Marinho V, Moysés S, Petersen P, et al. Global oral health inequalities: task group - implementation and delivery of oral health strategies. Adv Dent Res. 2011 May;23(2):259-67.

2. Sheiham A. Closing the gap in a generation: health equity through action on the social determinants of health. A report of the WHO Commission on Social Determinants of Health (CSDH) 2008. Community Dent Health. 2009 Mar;26(1):2-3.

3. Petersen P. The World Oral Health Report 2003: continuous improvement of oral health in the 21st century - the approach of the WHO Global Oral Health Programme. Community Dent Oral Epidemiol. 2003 Dec;31 Suppl 1:3 -24.

4. Petersen P. The burden of oral disease: challenges to improving oral health in the 21st century. Bull World Health Organ. 2005 Jan;83(1):3.

5. Watt RG. From victim blaming to upstream action: tackling the social determinants of oral health inequalities. Community Dent Oral Epidemiol. 2007 Feb;35(1):1-11.

6. Sanders AE, Slade GD, Turrell G, John Spencer A, Marcenes W. The shape of the socioeconomic-oral health gradient: implications for theoretical explanations. Community Dent Oral Epidemiol. 2006 Aug;34(4):310-9.

7. Starfield B. Equity and health: a perspective on nonrandom distribution of health in the population. Rev Panam Salud Publica. 2002 Dec;12(6):384-7.

8. Marmot M, Bell R. Social determinants and dental health. Adv Dent Res. 2011 May;23(2):201-6.

9. Leon DA, Walt G, Gilson L. Recent advances: International perspectives on health inequalities and policy. BMJ. $2001 \mathrm{Mar}$ 10;322(7286):591-4.

10. Adler NE, Rehkopf DH. U.S. disparities in health: descriptions, causes, and mechanisms. Annu Rev Public Health. 2008 Apr;29:235-52.

11. Kwan S, Petersen PE. Oral health: equity and social determinants. In: Blas E, Kurup AS, editors. Equity, social determinants and public health programmes. Geneva: World Health Organization; 2010. p. 159-176.

12. Wathen WF. International implications of "oral health in America: a report of the Surgeon General”. Quintessence Int. 2000 Nov-Dec;31(10):697.

13. Petersen PE, Bourgeois D, Ogawa H, Estupinan-Day S, Ndiaye C. The global burden of oral diseases and risks to oral health. Bull World Health Organ. 2005 Sep;83(9):661-9. family, community, and society.

Future improvements in oral health and a reduction in inequalities in oral health are dependent on the implementation of public health strategies focusing on the underlying determinants of oral diseases.

14. Watt RG. Strategies and approaches in oral disease prevention and health promotion. Bull World Health Organ. 2005 Sep;83(9):711-8.

15. Smedley BD, Syme SL. Promoting health: intervention strategies from social and behavioral research. Am J Health Promot. 2001 Jan-Feb;15(3):149-66.

16. Marmot M, Commission on Social Determinants of Health. Achieving health equity: from root causes to fair outcomes. Lancet. 2007 Sep 29;370(9593):1153-63.

17. McKinlay JB. Paradigmatic obstacles to improving the health of populations - implications for health policy. Salud Publica Mex. 1998 Jul-Aug;40(4):369-79.

18. Marmot M. Closing the health gap in a generation: the work of the Commission on Social Determinants of Health and its recommendations. Glob Health Promot. 2009 Mar;Suppl $1: 23-7$.

19. Williams DM. Global Oral Health Inequalities: The research agenda. Adv Dent Res. 2011 May;23(2):198-200.

20. Phelan JC, Link BG, Tehranifar P. Social conditions as fundamental causes of health inequalities: theory, evidence, and policy implications. J Health Soc Behav. 2010 Nov;51 Suppl:S28-40.

21. Marmot M, Allen J, Bell R, Goldblatt P. Building of the global movement for health equity: from Santiago to Rio and beyond. Lancet. 2012 Jan 14;379(9811):181-8.

22. Graham H. Social determinants and their unequal distribution: clarifying policy understandings. Milbank Q. 2004 March;82(1):101-24.

23. Edelstein BL, Chinn CH. Update on disparities in oral health and access to dental care for America's children. Acad Pediatr. 2009 Nov-Dec;9(6):415-9.

24. Do LG, Spencer AJ, Slade GD, Ha DH, Roberts-Thomson KF, Liu P. Trend of income-related inequality of child oral health in Australia. J Dent Res. 2010 Sep;89(9):959-64.

25. Dye BA, Arevalo O, Vargas CM. Trends in paediatric dental caries by poverty status in the United States, 1988-1994 and 1999-2004. Int J Paediatr Dent. 2010 Mar;20(2):132-43.

26. Bernabe $\mathrm{E}, \mathrm{Hobdell} \mathrm{MH}$. Is income inequality related to childhood dental caries in rich countries?. J Am Dent Assoc. 2010 Feb;141(2):143-9.

27. Pucca GA Jr, Costa JF, Chagas LD, Sivestre RM. Oral health policies in Brazil. Braz Oral Res. 2009;23 Suppl 1:9-16. 
28. Watt RG, Sheiham A. Integrating the common risk factor approach into a social determinants framework. Community Dent Oral Epidemiol. 2012 Aug;40(4):289-96.

29. Petersen PE, Kwan S. Equity, social determinants and public health programmes - the case of oral health. Community Dent Oral Epidemiol. 2011 Dec;39(6):481-7.

30. Petersen PE. Challenges to improvement of oral health in the 21st century - the approach of the WHO Global Oral Health Programme. Int Dent J. 2004 Dec;54(6 Suppl 1):329-43.

31. Harford J. Population ageing and dental care. Community Dent Oral Epidemiol. 2009 Apr;37(2):97-103.

32. Griffin SO, Jones JA, Brunson D, Griffin PM, Bailey WD. Burden of oral disease among older adults and implications for public health priorities. Am J Public Health. 2012 Mar;102(3):411-8.

33. Baelum V, van Palenstein Helderman W, Hugoson A, Yee R, Fejerskov O. A global perspective on changes in the burden of caries and periodontitis: implications for dentistry. J Oral Rehabil. 2007 Dec;34(12):872-906; discussion 940.

34. Sheiham A, Watt RG. The common risk factor approach: a rational basis for promoting oral health. Community Dent Oral Epidemiol. 2000 Dec;28(6):399-406.

35. Petersen PE. Priorities for research for oral health in the 21st century - the approach of the WHO Global Oral Health Programme. Community Dent Health. 2005 Jun;22(2):71-4.

36. Petersen PE. World Health Organization global policy for improvement of oral health - World Health Assembly 2007. Int Dent J. 2008 Jun;58(3):115-21.

37. Muntaner C, Sridharan S, Solar O, Benach J. Against unjust global distribution of power and money: the report of the WHO commission on the social determinants of health: global inequality and the future of public health policy. J Public Health Policy. 2009 Jul;30(2):163-75.

38. Pellegrini Filho A, Vettore MV. Brazilian studies on social determinants of health inequities. Cad Saude Publica. 2011;27 Suppl 2:S132-3.

39. Whitehead M, Popay J. Swimming upstream? Taking action on the social determinants of health inequalities. Soc Sci Med. 2010 Oct;71(7):1234-6; discussion 1254-8.

40. Robinson M. Equity, justice and the social determinants of health. Glob Health Promot. 2009 Mar;Suppl 1:48-51.

41. Moysés SJ, Moysés ST, McCarthy M, Sheiham A. Intra-urban differentials in child dental trauma in relation to healthy cities policies in Curitiba, Brazil. Health Place. 2006 Mar;12(1):48-64.
42. Moysés SJ, Moysés ST, Krempel MC. Avaliando o processo de construção de políticas públicas de promoção de saúde: a experiência de Curitiba. Cien Saude Colet. 2004 Jul-Sep;9(3):627-641.

43. Splieth Ch H, Innes N, Sohnel A. Evidence-based cariology in clinical and public health practice as part of the European Core Curriculum in Cariology. Eur J Dent Educ. 2011 Nov;15 Suppl 1(2011):45-51.

44. Junges R, Stello RS, Portella FF, Rosing CK, Samuel SM. Impact of the implantation of a new curriculum in the process of learning in a Faculty of Dentistry in Brazil. Braz Oral Res. 2011 Nov-Dec;25(6):478-84.

45. Zilbovicius C, de Araujo ME, Botazzo C, Frias AC, Junqueira SR, Junqueira CR. A paradigm shift in predoctoral dental curricula in Brazil: evaluating the process of change. J Dent Educ. 2011 Apr;75(4):557-64.

46. Kusma SZ, Moysés ST, Moysés SJ. [Health promotion: perspectives for evaluation of oral health in primary healthcare]. Cad Saude Publica. 2012 Jul;28 Suppl:s9-s19. Portuguese.

47. Moysés ST, Moysés SJ, Watt RG, Sheiham A. Associations between health promoting schools' policies and indicators of oral health in Brazil. Health Promot Int. 2003 Sep 1;18(3):20918.

48. Moysés SJ. Assim é se lhe parece! Cien Saude Colet. 2006 JanMar;11(1):21-4.

49. Cury JA, Tenuta LM, Ribeiro CC, Paes Leme AF. The importance of fluoride dentifrices to the current dental caries prevalence in Brazil. Braz Dent J. 2004 Mar;15(3):167-74.

50. Pitts N, Amaechi B, Niederman R, Acevedo AM, Vianna R, Ganss C, et al. Global oral health inequalities: dental caries task group - research agenda. Adv Dent Res. 2011 May;23(2):211-20.

51. Tenuta LM, Cury JA. Fluoride: its role in dentistry. Braz Oral Res. 2010;24 Suppl 1:9-17.

52. Petersen PE. Global policy for improvement of oral health in the 21st century - implications to oral health research of World Health Assembly 2007, World Health Organization. Community Dent Oral Epidemiol. 2009 Feb;37(1):1-8.

53. Monajem S. The WHO's action plan for oral health. Int J Dent Hyg. 2009 Feb;7(1):71-3.

54. Oral health: prevention is key. The Lancet. 2009 Jan 3;373(9657):1.

55. Benzian H, Hobdell M, Mackay J. Putting teeth into chronic diseases. The Lancet. 2011 Feb 5;377(9764):464. 